\title{
Antiobesity and Hypoglycaemic Effects of Aqueous Extract of Ibervillea sonorae in Mice Fed a High-Fat Diet with Fructose
}

\author{
Fabiola Rivera-Ramírez, ${ }^{1}$ Gerardo N. Escalona-Cardoso, ${ }^{1}$ Leticia Garduño-Siciliano, ${ }^{2}$ \\ Carlos Galaviz-Hernández, ${ }^{3}$ and Norma Paniagua-Castro ${ }^{1,4}$ \\ ${ }^{1}$ Department of Physiology, National School of Biological Sciences, National Polytechnic Institute, Prolongación de Carpio y Plan de \\ Ayala s/n Colonia, Plutarco Elías Calles, Delegación Miguel Hidalgo, 11340 Mexico City, DF, Mexico \\ ${ }^{2}$ Department of Pharmacy, National School of Biological Sciences, National Polytechnic Institute, Prolongación de Carpio y Plan de \\ Ayala s/n Colonia, Plutarco Elías Calles, Delegación Miguel Hidalgo, 11340 Mexico City, DF, Mexico \\ ${ }^{3}$ Department of Molecular Genetics, Interdisciplinary Research Center for Regional Integral Development, Sigma s/n Fraccionamiento \\ 20 de Noviembre II, 34220 Durango, DGO, Mexico \\ ${ }^{4}$ Escuela Nacional de Ciencias Biológicas, Instituto Politécnico Nacional, Avenida Wilfrido Massieu s/n, Esq. Manuel L. Stampa, \\ Col. Unidad Profesional Adolfo López Mateos, Delegación Gustavo A. Madero, 07738 Ciudad de México, DF, Mexico
}

Correspondence should be addressed to Norma Paniagua-Castro, npaniag@hotmail.com

Received 15 June 2011; Revised 16 August 2011; Accepted 5 September 2011

Academic Editor: Vickram Ramkumar

Copyright (๑) 2011 Fabiola Rivera-Ramírez et al. This is an open access article distributed under the Creative Commons Attribution License, which permits unrestricted use, distribution, and reproduction in any medium, provided the original work is properly cited.

\begin{abstract}
Obesity, type II diabetes, and hyperlipidaemia, which frequently coexist and are strongly associated with oxidative stress, increase the risk of cardiovascular disease. An increase in carbohydrate intake, especially of fructose, and a high-fat diet are both factors that contribute to the development of these metabolic disorders. In recent studies carried out in diabetic rats, authors reported that Ibervillea sonorae had hypoglycaemic activity; saponins and monoglycerides present in the plant could be responsible for the effects observed. In the present study, we determined the effects of an aqueous I. sonorae extract on a murine model of obesity and hyperglycaemia, induced by a high-calorie diet, and the relationship of these effects with hepatic oxidation. A high-fat diet over a period of 8 weeks induced weight gain in the mice and increased triglycerides and blood glucose levels. Simultaneous treatment with I. sonorae aqueous extracts, at doses of 100,200 , and $400 \mathrm{mg} / \mathrm{kg}$, decreased triglycerides and glycaemia levels, prevented an increase in body weight in a dose-dependent manner, and decreased hepatic lipid oxidation at a dose of $200 \mathrm{mg} / \mathrm{kg}$. These data suggest that the aqueous extract from I. sonorae root prevents obesity, dyslipidaemia, and hyperglycaemia induced by a hypercaloric diet; however, high doses may induce toxicity.
\end{abstract}

\section{Introduction}

Obesity is a global health problem and is associated with the development of chronic diseases such as hyperlipidaemias, type II diabetes, and cardiovascular complications. Oxidative stress is linked to obesity, and adipose tissue can produce adipokines that induce production of reactive oxygen species (ROS) that cause insulin resistance. All of these factors may contribute to metabolic syndrome [1]. It is estimated that genetic factors, high-fat diets, and sedentary lifestyles are the main factors underlying the development of these diseases $[2,3]$. In Mexico, as in other countries, a rise in the number of obesity cases in adults and children has been noted [4-6].
Other reports have demonstrated that high consumption of refined carbohydrates, especially fructose, can induce obesity and hyperglycaemia, with concomitant insulin resistance $[7,8]$. The primary recommendations to manage the disease include diet modification and physical exercise to achieve weight loss [9], followed by pharmacological treatment.

A variety of natural products have been proposed as pharmacological treatments for obesity. The products that can induce body weight reduction and prevent dietinduced obesity in animal models include crude extracts and compounds isolated from plants [10]. Therefore, they have also been recommended as an aid in prevention of obesity. Other natural products such as cinnamon [11], 
TABLE 1: Composition of the control and test diets.

\begin{tabular}{lcc}
\hline & Control $(\%)^{*}$ & HF $(\%)^{* *}$ \\
\hline Protein & 28.05 & 18.23 \\
Fat & 12.14 & 7.89 \\
Lard & 0 & 35.00 \\
Carbohydrate & 59.81 & 38.88 \\
Total (g) & 100 & 100 \\
\hline Calories (kcal) & 467.5 & 614.5 \\
\hline * Lab Chow 5012 diet. & \\
**Fructose (60\%) was administered by gavage (2.4 kcal).
\end{tabular}

green tea [12], and oats [13] have demonstrated antioxidant, hypoglycaemic, and hypolipidaemic properties. The use and acceptance of traditional medicine have increased in recent years $[14,15]$. In traditional Mexican medicine the root of Ibervillea sonorae (IS), colloquially known as "wareke," is widely used as a topical antibiotic, cathartic, antirheumatic [16], and, recently, hypoglycaemic [17]. Previously published pharmacological properties for IS root include antiviral and antifungal [18], cytotoxic [19], and hypoglycaemic effects. Alarcon-Aguilar et al. [20] demonstrated the hypoglycaemic action of dichloromethane-extracted IS on healthy and aloxane-induced diabetic mice [21]; however, its hypolipidaemic effects remain unclear. The present study evaluated the effect of the aqueous extract of IS on glucose and lipid levels as well as hepatic oxidation in mice fed a high-fat diet plus fructose.

\section{Materials and Methods}

2.1. Plant Material. The dried powder of Ibervillea sonorae (IS) root was purchased from Nutra Herbal (Mexico City) (http://www.nutraherbalmexico.com/). IS samples were water extracted at $90^{\circ} \mathrm{C}$ with $10 \mathrm{~g}$ sample per $100 \mathrm{~mL}$ water and allowed to cool at room temperature. The extract was then filtered and freeze-dried (Freeze Dry System/Freezone 4.5, LABCONCO, USA). The extraction yield for the resulting brown powder was $8 \%$, and it was stored at $-20^{\circ} \mathrm{C}$ until use. Doses of 100,200 , and $400 \mathrm{mg} / \mathrm{kg}$ lyophilised extract were dissolved in distilled water and administered daily by gavage.

2.2. High-Fat Diet. The high-fat diet was prepared by adding $35 \%$ lard to a ground standard diet. Fructose (Cedrosa SA Mexico) solution (60\%) was administered daily by gavage. Food intake was measured every day, and body weight was measured once every two days. The composition of the diets is shown in Table 1.

2.3. Animals. Male ICR mice (Biorepository of the National School of Biological Sciences) weighing 25-30 g were housed in a room at a constant temperature of $22 \pm 1^{\circ} \mathrm{C}$ and a $12 \mathrm{~h}$ light/dark cycle (lights on at 9:00 AM) and were given food and water ad libitum. All experiments were approved by the Laboratory Animal Care Committee of the National School of Biological Sciences (National Polytechnic Institute)
TABLE 2: Treatment groups.

\begin{tabular}{ll}
\hline Groups & Treatment $(\mathrm{mg} / \mathrm{kg}$ body weight) \\
\hline 1 & Control \\
2 & High fat-fructose (HFF) \\
3 & Ibervillea sonorae (IS) 400 \\
4 & HFF + IS 100 \\
5 & HFF + IS 200 \\
6 & HFF + IS 400 \\
\hline
\end{tabular}

and were conducted in compliance with the Mexican Official Standard (NOM-062-200-1999) technical specifications for the production, care, and use of laboratory animals.

The animals were distributed into 6 groups of 10 animals each and were fed a high-fat diet plus fructose (HFF). Mice receiving the aqueous IS extract were dosed for 8 weeks in parallel, as detailed in Table 2.

2.4. Biochemical Parameters. After eight weeks of treatment, the animals were fasted for 8 hours and then sacrificed. Blood was collected by retroorbital puncture, and serum was prepared by centrifuging the blood at $3000 \mathrm{rpm}$ for 20 minutes. The levels of serum glucose, total cholesterol (TC), HDL cholesterol (HDL-C), and triglycerides (TGs) were determined to analyse using the automatic Selectra analyser (Modelo Vitalab 2), with commercial kits (RANDOX). The Friedewald formula [22] was used to calculate serum low-density lipoprotein cholesterol (LDL-C) values and atherogenic index as follows: LDL-C $=$ TC-(HDL-C + TG/5); atherogenic index $=($ TC-HDL-C)/HDL-C. The liver and periepididymal fat were also weighed.

2.5. Hepatic Lipid Peroxidation Assay. The hepatic weight was recorded and lipid peroxidation assessed by measuring malondialdehyde (MDA) content as described by Buege and Aust [23], with minor modifications. Briefly, $50 \mathrm{mg}$ liver was homogenised in $0.5 \mathrm{~mL}$ cold phosphate buffer ( $\mathrm{pH} 7.0$ ), followed immediately with the addition of $1 \mathrm{~mL}$ of a reagent containing trichloroacetic acid (TCA), thiobarbituric acid (TBA) and $\mathrm{HCl}(15 \%(\mathrm{w} / \mathrm{v}), 0.375 \%(\mathrm{w} / \mathrm{v})$, and $0.25 \mathrm{~N}$, resp.) to the homogenate. The solution was then heated for $30 \mathrm{~min}$ in a boiling water bath. After cooling, the flocculent precipitate was removed by centrifugation at $1000 \mathrm{~g}$ for $10 \mathrm{~min}$. A Bio-Mini Shimadzu Spectrophotometer was used to determine absorbance at $532 \mathrm{~nm}$. A sample containing reagent only was used as a blank. The MDA content was calculated using an extinction coefficient of $1.56 \times 10^{-5} \mathrm{M}^{-1} \mathrm{~cm}^{-1}$. The protein content was determined using the Coomassie blue method [24], with bovine serum albumin (BSA) as the standard.

2.6. Statistical Analysis. Data were analysed with one-way ANOVAs followed by Holm-Sidak post hoc tests, with significance set to $P<0.05$. Food consumption was analysed using two-way ANOVA repeated measures tests followed by Tukey's post hoc tests, with significance set to $P<0.05$. All analyses were performed using Sigma Stat (10.0). 


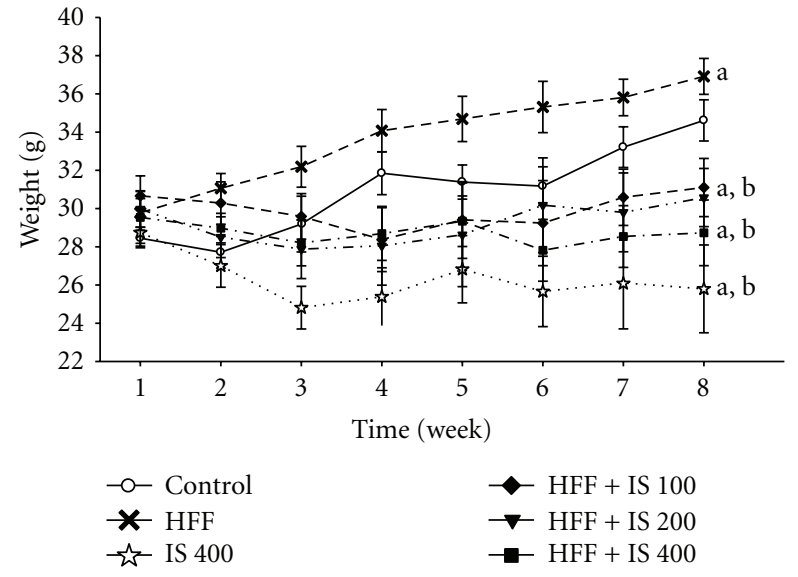

Figure 1: Body weight of mice fed a high-fat diet plus fructose (HFF) and treated with $I$. sonorae (IS) for 8 weeks; a: significant difference compared to control; b: significant difference compared to HFF, $P<0.001$ (one-way ANOVA, Holm-Sidak post hoc test, $n=10$ per group).

\section{Results}

3.1. Body Weight. The effect of a high-fat diet plus fructose (HFF) on the body weight of mice is shown in Figure 1. During the 8 weeks of treatment, the weight of the HFF group increased significantly from the first week until the end of treatment when compared with the control group. Mice receiving IS only $(400 \mathrm{mg} / \mathrm{kg})$ underwent a $6 \%$ loss in weight relative to the starting weight. All doses of IS (100, 200, and $400 \mathrm{mg} / \mathrm{kg}$ ) prevented weight gain in mice fed HFF.

3.2. Food Intake. Throughout treatment, the mice that received the HFF diet consumed less food than the control group, but their calorie intake was higher (Figures 2(a) and 2(b)). Coadministration of the aqueous extract of IS reduced food intake in all groups, with a greater effect in groups treated with 200 and $400 \mathrm{mg} / \mathrm{kg}$ (Figure 2).

Compared with control-fed mice, the amount of periepididymal fat was higher in mice fed the HFF diet. All three doses of IS extract resulted in significantly reduced fat deposition in this region (Figure 3 ).

3.3. Biochemical Parameters. The HFF diet increased triglyceride levels 1.9 -fold (from 0.88 to $1.7 \mathrm{mmol} / \mathrm{L}$ ), total cholesterol 1.8-fold (from 18.6 to $35.2 \mathrm{mmol} / \mathrm{L}$ ), HDL-C 2.1-fold (from 9.5 to $20.8 \mathrm{mmol} / \mathrm{L}$ ), LDL-C 1.2 -fold (from 11 to $13.4 \mathrm{mmol} / \mathrm{L}$ ), and glucose levels from 84.4 to $169.8 \mathrm{mg} / \mathrm{dL}$. Both triglycerides and blood glucose levels in mice fed the HFF diet were significantly different from mice fed with control diet $(P<0.05$, Table 3$)$.

The $400 \mathrm{mg} / \mathrm{kg}$ dose of IS increased cholesterol and LDL levels when administered alone. However, in HFF-fed mice, triglyceride and glucose levels were reduced in a dosedependent manner by IS, with the highest dose inducing a significant reduction in these parameters. In control-fed mice, IS (400 mg/kg) increased the lipid profile and atherogenic index.
3.4. Hepatic Lipid Peroxidation. No significant differences were found in liver weight of mice fed the HFF diet and/or treated with IS (Figure 4(a)). However, the group receiving the HFF diet had higher levels of hepatic lipid peroxidation than control-fed mice (Figure 4(b)). Co-administration of $200 \mathrm{mg} / \mathrm{kg}$ of IS decreased oxidation levels; however, the lower $(100 \mathrm{mg} / \mathrm{kg})$ and higher $(400 \mathrm{mg} / \mathrm{kg})$ doses showed no liver protection.

\section{Discussion}

Fructose is a sweetener in sugary drinks, and its consumption has increased in recent years. Sugar metabolism occurs primarily in the liver, where a high fructose flux leads to enhanced accumulation of hepatic triglycerides, resulting in impaired glucose and lipid metabolism and increased cardiovascular risk [25-27]. Diets high in fat also result in increased levels of blood lipids and glucose; therefore, it is proposed that an overexpression of hepatic 1-6 bisphosphatase, which is involved in gluconeogenesis, may be responsible for hyperglycaemia in type II diabetes [28]. Observed increases in body weight after consumption of a high-fat diet are mainly due to the hyperplasticity and hypertrophy of adipose tissue [29]. Furthermore, studies in humans and in animal models suggest that dietary components such as high fat and fructose can affect fatty infiltration and lipid peroxidation in various diseases of the liver [30, 31]. Extensive interventions are recommended when treating obesity and hyperglycaemia, including diet control, exercise, and pharmacological interventions. However, many patients do not respond to treatment and may present with adverse treatment effects, indicating a need for efficacious alternatives. Some plants contain active substances with important pharmacological activities, and they represent an excellent alternative. In the murine model used in this study, we found the expected HFF-induced increase in body weight and periepididymal fat as well as hyperglycaemia and hypertriglyceridemia. IS treatment prevented these alterations, suggesting that the aqueous extract of IS exhibits pharmacological antiobesity effects. Our results show that the HFF diet increased body weight in mice, even though food intake was lower compared with the control diet. The HFF diet provides more calories than a normal diet, resulting in a high level of fat storage in the periepididymal region. IS administration prevented weight gain and reduced the consumption of food and calories in HFF-fed mice. However, $400 \mathrm{mg} / \mathrm{kg}$ IS aqueous extract alone reduced food intake and caused weight loss in mice. This could be a toxic effect in normal mice fed a normal diet, but this effect had not been reported before.

The HFF diet increased cholesterol, triglycerides, and blood glucose levels, as well as HDL-C, suggesting that the HFF diet is not atherogenic. Co-administration of IS extract, at $400 \mathrm{mg} / \mathrm{kg}$, reduced triglycerides, cholesterol, and glycaemia levels, but lower doses did not show a similar activity. IS aqueous extract alone $(400 \mathrm{mg} / \mathrm{kg})$ increased triglycerides, cholesterol, and LDL-C but decreased HDL-C, which suggests an atherogenic effect in normal mice; a result not reported previously. Andrade-Cetto and Heinrich [18] and Alarcon-Aguilar et al. [32] reported that aqueous and 


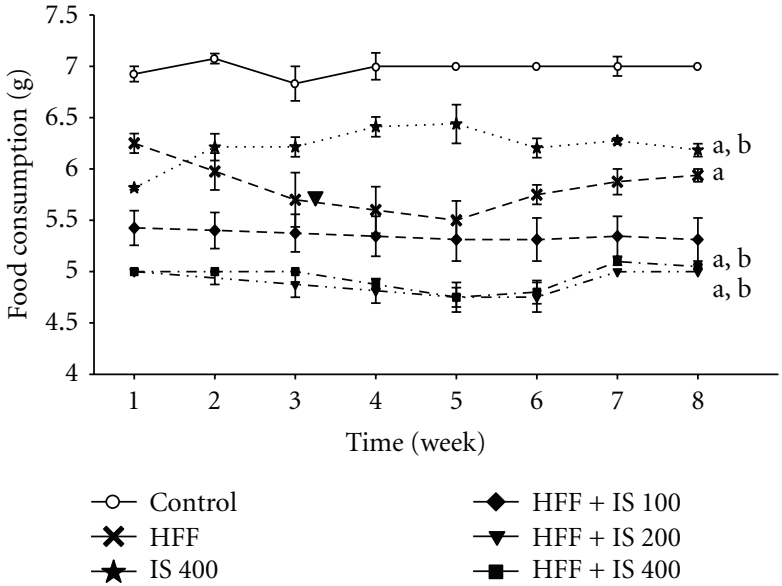

(a)

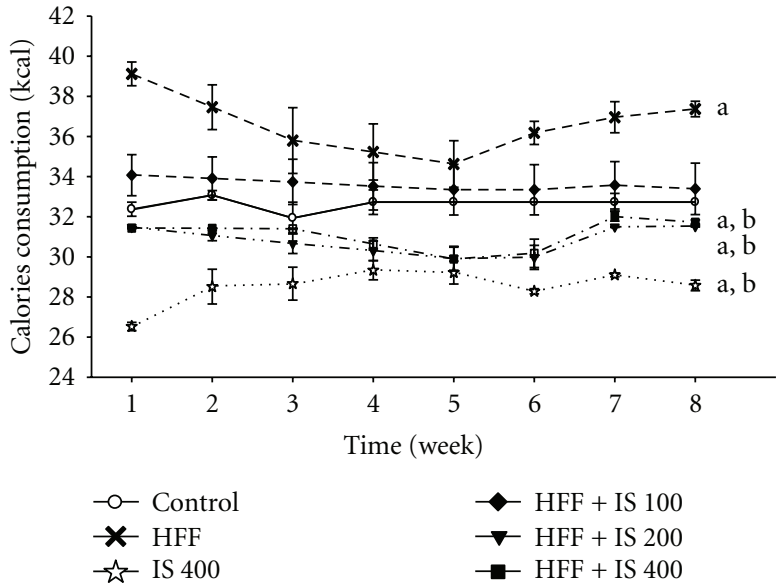

(b)

FIGURE 2: Food and calorie consumption (kcal) in mice fed a high-fat diet plus fructose (HFF) and treated with I. sonorae (IS) for 8 weeks; a: significant difference compared to control; b: significant difference compared to HFF, $P<0.05$ (one-way ANOVA, Tukey's post hoc test).

TABLE 3: Glycaemia and lipid profile in male mice fed HFF and/or IS for 8 weeks.

\begin{tabular}{lcccccc}
\hline & Control & IS $400 \mathrm{mg} / \mathrm{kg}$ & HFF & HFF + IS 100 mg/kg & HFF + IS 200 mg/kg & HFF + IS 400 mg/kg \\
\hline Triglycerides (mmol/L) & $0.9 \pm 0.05$ & $1.15 \pm 0.2^{\mathrm{a}}$ & $1.7 \pm 0.2^{\mathrm{a}}$ & $1.36 \pm 0.2$ & $1.2 \pm 0.11$ & $0.96 \pm 0.11^{\mathrm{b}}$ \\
Cholesterol (mmol/L) & $18.6 \pm 0.4$ & $29 \pm 2.2^{\mathrm{a}}$ & $35 \pm 2.8^{\mathrm{a}}$ & $38.8 \pm 3.8^{\mathrm{a}}$ & $32.3 \pm 3.8^{\mathrm{a}}$ & $28.4 \pm 1.4^{\mathrm{b}}$ \\
HDL-C (mmol/L) & $9.5 \pm 0.6$ & $7.7 \pm 1.6^{\mathrm{b}}$ & $20.8 \pm 1.4^{\mathrm{a}}$ & $16.4 \pm 1.7^{\mathrm{a}}$ & $16.1 \pm 0.5^{\mathrm{a}}$ & $16.4 \pm 1.4^{\mathrm{a}}$ \\
LDL-C (mmol/L) & $12.1 \pm 1.7$ & $21.8 \pm 6.1^{\mathrm{a}}$ & $15.0 \pm 3.2$ & $23.1 \pm 4.5^{\mathrm{a}}$ & $16.7 \pm 0.01$ & $12.40 \pm 1.4$ \\
Glycaemia (mg/dL) & $84.4 \pm 6.7$ & $96 \pm 7.1$ & $169.8 \pm 13.9^{\mathrm{a}}$ & $141 \pm 21.4^{\mathrm{a}}$ & $128.3 \pm 13.2^{\mathrm{a}}$ & $91.8 \pm 7.1^{\mathrm{b}}$ \\
Atherogenic index & $0.9 \pm 0.2$ & $2.8 \pm 1.1^{\mathrm{a}}$ & $0.7 \pm 0.9$ & $1.4 \pm 0.7$ & $1.0 \pm 0.09$ & $0.7 \pm 1.2$ \\
\hline
\end{tabular}

Data are mean \pm S.E. HFF: high fat and fructose; IS: Ibervillea sonorae; a: significant difference compared to Control; b: significant difference compared to HFF, $P<0.05$ (one-way ANOVA, Tukey's post hoc test).

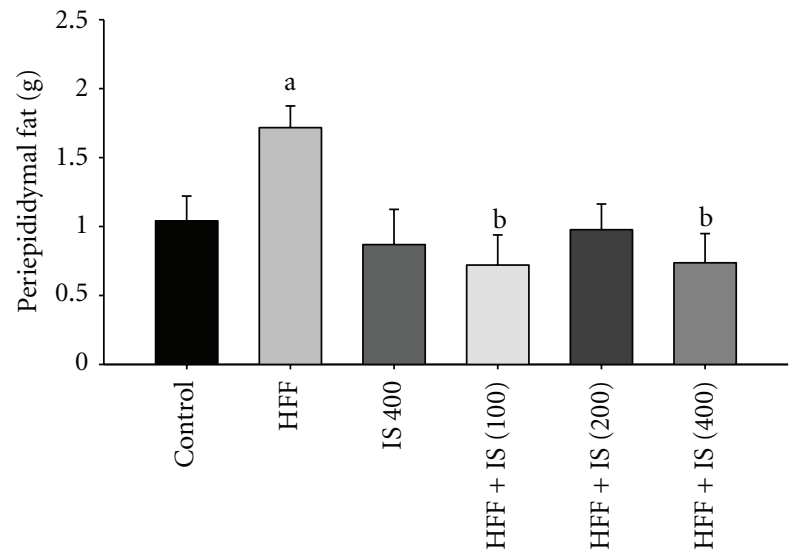

Figure 3: Periepididymal fat in mice fed control diet, or HFF and/or IS for 8 weeks; a: significant difference compared to control; b: significant difference compared to HFF, $P<0.05$ (one-way ANOVA, Tukey's post hoc test).

dichloromethane extracted IS reduced blood glucose levels significantly in mice with alloxan-induced diabetes. The authors suggested that the hypoglycaemic effect may have been due to an improvement in insulin sensitivity and/or reduced insulin resistance. However, functional pancreatic $\beta$ cells were required to achieve these effects, which suggests a potential therapeutic use of IS for type II diabetes. As observed in results from the liver TBARS assay, our data showed increased hepatic lipid peroxidation in the HFFfed group. These results indicated that eight weeks of HFF diet induced oxidative stress that could damage the liver. IS extract dosed at $200 \mathrm{mg} / \mathrm{kg}$ reduced hepatic oxidation in HFF-fed mice, while lower and higher doses had no effect.

The antiobesity effects of IS have not been reported previously. Although the mechanism of action of IS is not clearly established, it has been proposed to result from constituents such as saponins and flavonoids [33]. Studies using other plants of the same family, such as Momordica charantia (MC), have suggested that the blood-glucoselowering effect of IS is through inhibition of glucose uptake, facilitation of glucose entrance into skeletal muscle cells, and increased insulin sensitivity. We also observed a lipidlowering effect in HFF-fed mice, and this was mainly attributed to saponins present in the aqueous extract [34, 35]. Other authors also reported that fractions of $\mathrm{MC}$ inhibited disaccharidase, which had a marked influence on carbohydrate absorption and inhibited elevation of blood glucose. These results suggest that the main constituent 


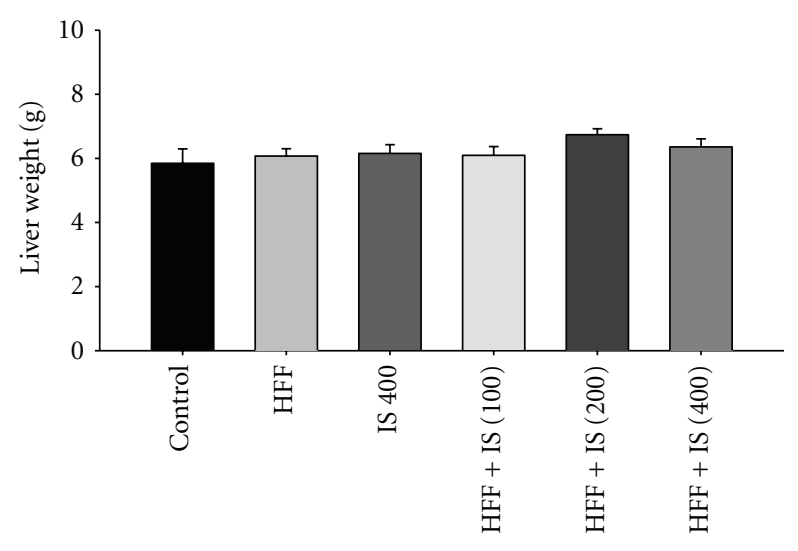

(a)

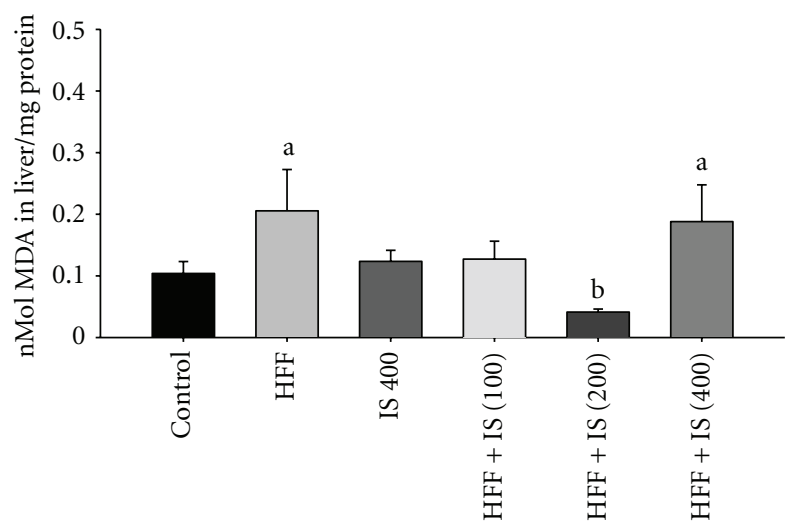

(b)

FIgURE 4: (a) Weight and (b) lipid peroxidation levels in liver of mice fed a high-fat diet plus fructose (HFF) and treated with I. sonorae (IS) for 8 weeks; a: significant difference compared to Control; b: significant difference compared to HFF, $P<0.05$ (one way ANOVA, Tukey's post hoc test).

of MC that underlies its hypoglycaemic effect could also inhibit pancreatic lipase and, consequently, the intestinal absorption of lipids thus contributes to the hypolipidemic and antiobesity properties of MC [34]. Because IS belongs to the same family as $\mathrm{MC}$, it is expected to have similar constituents that could contribute to its activity. HernándezGalicia et al. [21] reported that dichloromethane-extracted IS contained monoglycerides with antioxidant effects, which was observed only with the dose of $200 \mathrm{mg} / \mathrm{kg}$, in our study.

In conclusion, a HFF diet increased weight gain, cholesterol, triglycerides, blood glucose levels, and hepatic lipid peroxidation in mice. Aqueous extracts of IS $(400 \mathrm{mg} / \mathrm{kg})$ exhibited antiobesity effects and reduced glycaemia and hypotriglyceridemic effects in HFF-diet-induced obese and hyperglycaemic mice. The IS extract alone, at $400 \mathrm{mg} / \mathrm{kg}$, decreased body weight and increased the atherogenic index. However, further investigations are required to assess the possible toxicity of Ibervillea sonorae.

\section{Conflict of Interests}

The authors declare that they have no competing interests.

\section{Acknowledgments}

F. Rivera-Ramírez thanks PIFI, Instituto Politécnico Nacional and CONACYT for graduate scholarships awarded. N. Paniagua-Castro, G. N. Escalona-Cardoso, L. Garduño-Siciliano, and C. Galaviz are fellows of EDI and COFAA/IPN programs.

\section{References}

[1] S. A. M. Fernández, "Los radicales libres en las enfermedades: obesidad," in Los Sntioxidantes y Las Enfermedades Crónico Degenerativas, G. J. A. Morales, S. A. M. Fernández, A. M. Bautista, M. N. Vargas, and S. E. O. Madrigal, Eds., vol. 2, chapter 23, pp. 411-428, Universidad Autónoma del Estado de Hidalgo, México, 2010.

[2] M. E. D'Alessandro, A. Chicco, J. C. Basabe, and Y. B. Lombardo, "Relación lípidos y resistencia insulínica en un modelo experimental de dislipemia inducido por dieta rica en sacarosa," Revista Argentina de Endocrinologia y Metabolismo, vol. 43, no. 1, pp. 3-15, 2006.

[3] M. Massi-Benedetti and M. Orsini-Federici, "Treatment of type 2 diabetes with combined therapy: what are the pros and cons?" Diabetes Care, vol. 31, pp. S131-135, 2008.

[4] S. Barquera, M. Flores, G. Olaiz-Fernández et al., "Dyslipidemias and obesity in México," Salud Pública de México, vol. 49, supplement 3, pp. S338-S347, 2007.

[5] V. Farah, K. M. Elased, and M. Morris, "Genetic and dietary interactions: role of angiotensin AT1a receptors in response to a high-fructose diet," American Journal of Physiology-Heart and Circulatory Physiology, vol. 293, no. 2, pp. H1083-H1089, 2007.

[6] C. A. Aguilar-Salinas, F. J. Gómez-Pérez, J. Rull, S. Villalpando, S. Barquera, and R. Rojas, "Prevalence of dyslipidemias in the Mexican National Health and Nutrition Survey 2006," Salud Pública de México, vol. 52, supplement 1, pp. S44-S53, 2010.

[7] D. Huang, T. Dhawan, S. Young, W. H. Yong, L. G. Boros, and A. P. Heaney, "Fructose impairs glucose-induced hepatic triglyceride synthesis," Lipids in Health and Disease, vol. 10, p. 20, 2011.

[8] C. J. C. S. Meirelles, L. A. Oliveira, A. A. Jordão, and A. M. Navarro, "Metabolic effects of the ingestion of different fructose sources in rats," Experimental and Clinical Endocrinology and Diabetes, vol. 119, no. 4, pp. 218-220, 2011.

[9] C. P. Marinangeli and P. J. Jones, "Plant sterols, marinederived omega-3 fatty acids and other functional ingredients: a new frontier for treating hyperlipidemia," Nutrition and Metabolism, vol. 7, pp. 76-83, 2010.

[10] J. T. Xie, C. Z. Wang, M. Ni et al., "American ginseng berry juice intake reduces blood glucose and body weight in ob/ob mice," Journal of Food Science, vol. 72, no. 8, pp. S590-S594, 2007.

[11] A. M. Roussel, I. Hininger, R. Benaraba, T. N. Ziegenfuss, and R. A. Anderson, "Antioxidant effects of a cinnamon extract in people with impaired fasting glucose that are overweight or obese," Journal of the American College of Nutrition, vol. 28, no. 1, pp. 16-21, 2009.

[12] C. Cabrera, R. Artacho, and R. Giménez, "Beneficial effects of green tea-a review," Journal of the American College of Nutrition, vol. 25, no. 2, pp. 79-99, 2006.

[13] D. L. Katz, M. A. Evans, W. Chan et al., "Oats, antioxidants and endothelial function in overweight, dyslipidemic adults," Journal of the American College of Nutrition, vol. 23, no. 5, pp. 397-403, 2004. 
[14] S. Megalli, F. Aktan, N. M. Davies, and B. D. Roufogalis, "Phytopreventive anti-hyperlipidemic effects of Gynostemma pentaphyllum in rats," Journal of Pharmacy and Pharmaceutical Sciences, vol. 8, no. 3, pp. 507-515, 2005.

[15] E. Ruiz-Bustos, C. Velazquez, A. Garibay-Escobar et al., "Antibacterial and antifungal activities of some Mexican medicinal plants," Journal of Medicinal Food, vol. 12, no. 6, pp. 1398-1402, 2009.

[16] C. López, P. Y. Shanley, and A. Fantini, Eds., Riches of the Forest: Fruits, Oils, Remedies and Handicrafts in Latin America, CIFOR / DFID / EC / Overbrook Foundation, Indonesia, 2004.

[17] I. Pfefferkirn, Descripción de la Provincial de Sonora, Libro 1, Gobierno del Estado de Sonora, Hermosillo, Sonora, México, 1983.

[18] A. Andrade-Cetto and M. Heinrich, "Mexican plants with hypoglycaemic effect used in the treatment of diabetes," Journal of Ethnopharmacology, vol. 99, no. 3, pp. 325-348, 2005.

[19] E. Vega-Avila, A. Espejo-Serna, F. Alarcón-Aguilar, and R. Velasco-Lezama, "Cytotoxic activity of four Mexican medicinal plants," Proceedings of the Western Pharmacology Society, vol. 52, pp. 78-82, 2009.

[20] F. J. Alarcon-Aguilar, F. Calzada-Bermejo, E. HernandezGalicia, C. Ruiz-Angeles, and R. Roman-Ramos, "Acute and chronic hypoglycemic effect of Ibervillea sonorae root extracts-II," Journal of Ethnopharmacology, vol. 97, no. 3, pp. 447-452, 2005.

[21] E. Hernández-Galicia, F. Calzada, R. Roman-Ramos, and F. J. Alarcón-Aguilar, "Monoglycerides and fatty acids from Ibervillea sonorae root: isolation and hypoglycemic activity," Planta Medica, vol. 73, no. 3, pp. 236-240, 2007.

[22] W. T. Friedewald, R. I. Levy, and D. S. Fredrickson, "Estimation of the concentration of low-density lipoprotein cholesterol in plasma, without use of the preparative ultracentrifuge," Clinical Chemistry, vol. 18, no. 6, pp. 499-502, 1972.

[23] J. A. Buege and S. D. Aust, "Microsomal lipid peroxidation," Methods in Enzymology, vol. 52, pp. 302-310, 1978.

[24] M. M. Bradford, "A rapid and sensitive method for the quantitation of microgram quantities of protein utilizing the principle of protein dye binding," Analytical Biochemistry, vol. 72, no. 1-2, pp. 248-254, 1976.

[25] S. W. Rizkalla, "Health implications of fructose consumption: a review of recent data," Nutrition and Metabolism, vol. 7, p. 82, 2010.

[26] N. Wiernsperger, A. Geleon, and J. R. Rapin, "Fructose and cardiometablic disorders: the controversy will, and must continue," Clinics, vol. 65, no. 7, pp. 729-738, 2010.

[27] S. M. Hofmann and M. H. Tschöp, "Dietary sugars: a fat difference," Journal of Clinical Investigation, vol. 119, no. 5, pp. 1089-1092, 2009.

[28] S. Visinoni, B. C. Fam, A. Blair et al., "Increased glucose production in mice overexpressing human fructose-1,6bisphosphatase in the liver," American Journal of PhysiologyEndocrinology and Metabolism, vol. 295, no. 5, pp. E1132E1141, 2008.

[29] H. Du, J. S. You, X. Zhao, J. Y. Park, S. H. Kim, and K. J. Chang, "Antiobesity and hypolipidemic effects of lotus leaf hot water extract with taurine supplementation in rats fed a high fat diet," Journal of Biomedical Science, vol. 17, no. 1, pp. S42-S47, 2010.

[30] D. P. Arçari, W. Bartchewsky, T. W. dos Santos et al., "Antiobesity effects of yerba maté extract (Ilex paraguariensis) in high-fat diet-induced obese mice," Obesity, vol. 17, no. 12, pp. 2127-2133, 2009.
[31] S. Xolalpa-Molina, "Flora medicinal Mayo de la región de El Fuete y Choix, Sinaloa," in Biblioteca de la Medicina Tradicional Mexicana, Instituto Nacional Indigenista, Ed., pp. 363-411, Instituto Nacional Indigenista, México, 1994.

[32] F. J. Alarcon-Aguilar, A. E. Campos-Sepulveda, S. XolalpaMolina, E. Hernandez-Galicia, and R. Roman-Ramos, "Hypoglycaemic activity of Ibervillea sonorae roots in healthy and diabetic mice and rats," Pharmaceutical Biology, vol. 40, no. 8, pp. 570-575, 2002.

[33] R. E. Moreno, A. J. Velázquez, D. T. G. Valencia, G. A. B. Piña, and S. M. A. Ramírez, Análisis Fitoquímico Preliminar de Ibervillea Sonorae, Encuentro de Biotecnología, Mazatlán, México, 2010.

[34] Y. Oishi, T. Sakamoto, H. Udagawa et al., "Inhibition of increases in blood glucose and serum neutral fat by momordica charantia saponin fraction," Bioscience, Biotechnology and Biochemistry, vol. 71, no. 3, pp. 735-740, 2007.

[35] C. Han, Q. Hui, and Y. Wang, "Hypoglycaemic activity of saponin fraction extracted from Momordica charantia in PEG/salt aqueous two-phase systems," Natural Product Research, vol. 22, no. 13, pp. 1112-1119, 2008. 

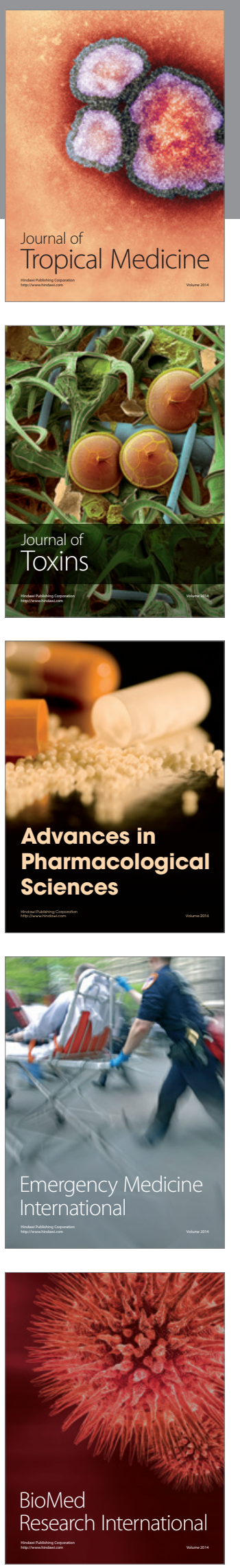
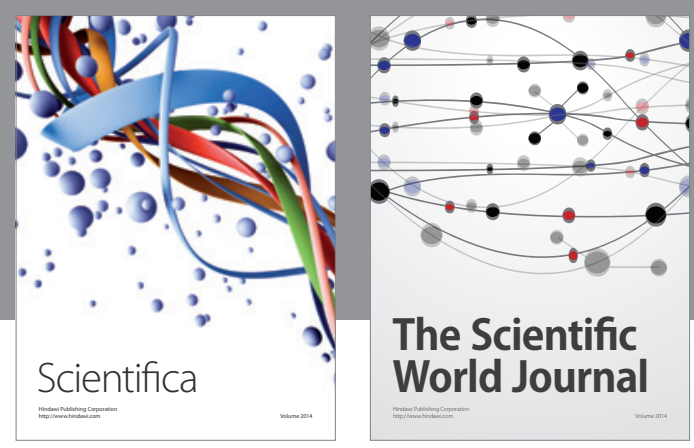

The Scientific World Journal
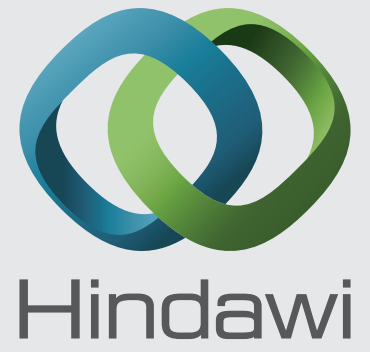

Submit your manuscripts at

http://www.hindawi.com
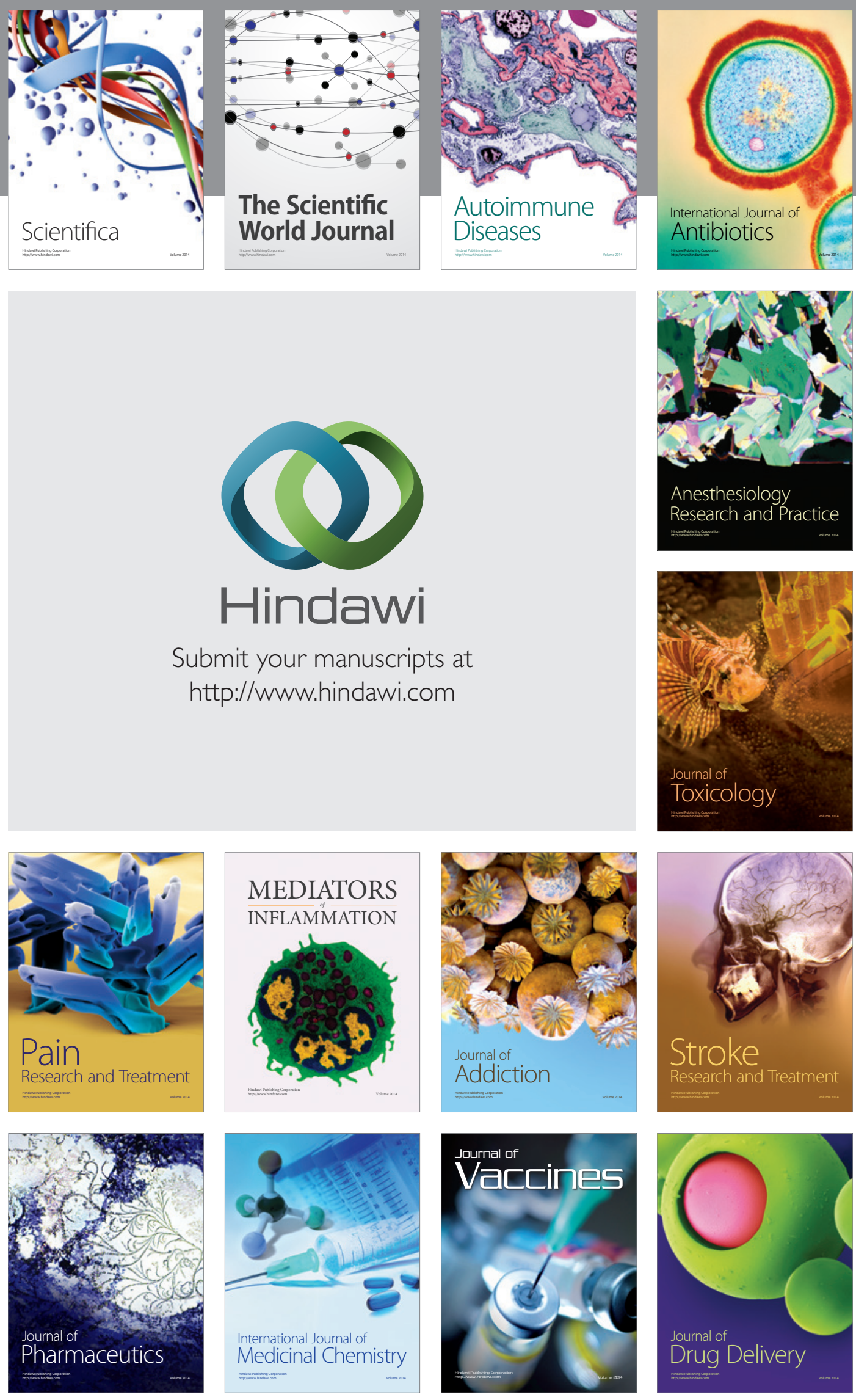